\title{
Motor Unit Recruitment Plays an Important Role in Determining the Relationship Between Muscle Force and Force Variability
}

\author{
Wan X Yao*, William M Land and Yufei Huang \\ Department of Kinesiology, Health, \& Nutrition College of Education \& Human Development, The University of Texas at San Antonio, San Antonio, USA
}

Received: 制: July 23, 2018; Published: 制 September 10, 2018

*Corresponding author: Wan X Yao, Department of Kinesiology, Health, \& Nutrition College of Education \& Human Development, The University of Texas at San Antonio, San Antonio, USA

\begin{abstract}
Literature shows that force variability increases when force levels increase. However, this constant increase occurs only to a certain point (e.g., at around $50 \%$ of maximum voluntary contraction (MVC) and $80 \% \mathrm{MVC}$ ). After this point, the increase of force variability either slows [1,2] or stops [3-5]. The potential underlying mechanism accounting for the changing rate of increase in force variability is discussed in this brief review. It concludes that among several factors, motor-unit recruitment appears to be the most important factor in determining the relationship between force and force variability although both motor unit discharge rate variability and synchronization have a significant impact on force variability as well.
\end{abstract}

Keywords: Motor Unit Recruitment; Discharge Rate; Motor Unit Synchronization; Force Variability

\section{Introduction}

Force variability has been observed across many studies where people attempt to produce a target level of force [1, 3-10]. Recently, Christou et al. [1] examined participants performing an isometric leg extension and found that force variability increased almost linearly as the level of force increased up to $60 \%$ MVC. After this point, force variability continued to increase, but at a much slower rate. Similar findings were also reported in a study with an isometric hand-grip tasks [10], and in a study with isometric abduction of the first dorsal interosseous muscle [2].

Force variability and its outcome has traditionally been viewed as a by-product of perceptual-motor noise imposed on a deterministic signal [3,11-13]. However, a study by Slifkin \& Newell [9] indicated that the variability of motor responses might not be caused by the perceptual- motor noise. In their study [9], participants were required to maintain isometric force for extended periods of time at different levels of maximum voluntary contraction.They found that force variability increased exponentially as a function of force level. However, the signal-to-noise ratio, as well as measures of noise in both the time (approximate entropy) and frequency (power spectrum) domains, changed according to an inverted U-shaped function over the range of force levels. Based on this finding, Slifkin \& Newell [9] claimed that force variability was not directly related to perceptual- motor noise. Instead, in a separate but related study, Slifkin \& Newell [10] hypothesized that motor-unit recruitment
(MUR) and discharge rate (DR) might play a role in the relationship between force and force variability. Their proposal seems to be supported by the findings from both empirical $[2,14]$ and computer simulation studies [15-16]. In addition, previous research [15-17] has also reported a significant effect of motor-unit synchronization (MUS, a measure of the correlated discharge of action potentials among motor units) on force variability.

A motor unit is defined as a motor neuron and all muscle fibers innervated by the neuron. It has been known for decades that muscle force is gradated by two mechanisms, namely MUR and DR $[17,18]$. Several studies have found that MUR is completed at about $40 \%$ of the MVC for small muscle groups such as hand muscles or at about $80 \%$ of the MVC for large muscle groups $[19,20]$. It is interesting to note that the maximum force variability (e.g., represented by the standard deviation of force productions at each estimated force levels) observed in Moritz et al. [2] study and Christou et al. [1] study were at approximately 50\% and 70\% MVR, respectively, which were close to the range at which MUR is completed in small and large muscles. Putting together, the relationship between muscle force and its variability could be directly related to the behavior of motor units. Therefore, studies on the effect of MUR and DR on force and its variability are important to be highlighted, and the purpose of this article is to provide a comprehensive review on the role of MUR and DR in affecting the relationship between force and its variability. 


\section{Motor-Unit Recruitment}

A computer simulation study by Yao [15] is one of the few studies that have focused on examining the role of MUC and DR in determining the relationship between muscle force and its variability. In the study [15], 10 levels of the maximum force (MVC) were simulated, ranging from 10 to $100 \%$ of MVC. There were two recruitment conditions, one condition (40\%MUR) recruited all motor units at $40 \%$ of the MVC level, and the other (50\%MUR) recruited all motor units at $50 \%$ of the MVC, this allowed the $40 \%$ MUR condition to have a greater number of motor units than the 50\%MUR group before the level of the simulated force reached $50 \%$ of the MVC. Similar to the empirical findings of Moritz et al. [2], Yao's [15] simulation also found that force variability increased at a faster rate at low force levels (i.e., from 10 to $50 \%$ of MVC), whereas after this point (i.e., from 50 to $100 \%$ of MVC), the rate of increasing variability coinciding with increased force was greatly reduced (Figure 1A). It should be noted that $50 \%$ of MVC in the simulation was the point where the MUR completed in one of the two conditions. Although Moritz et al. [2] did not measure the whole motor unit pool and could not know exactly where the completion of MUR occurred in their study, the completion of MUR most likely happened around the point (i.e., approximately 50\% of the MVC) where the increasing rate of the variability slowed down according to previous research [20]. The findings from the two studies [2,15] indicate that the initial fast rate of increase in force variability at low force levels (i.e., before $50 \% \mathrm{MOV}$ ) could be due to the increase of the number of motor units recruited.

\section{Discharge Rate}

However, it is premature to claim that MUR is more important than the DR in determining the relationship of force and its variability because both the number of MUR and DR change at lower force levels. The superiority of MUR in determining the relationship is revealed when comparing the results of the variability and force in the two simulated conditions (i.e., $40 \%$ MUR group and 50\%MUR group). In the simulation study [15], the $40 \%$ MUR group showed consistently greater DR than the 50\%MUR group (Figure 1B). However, the $40 \%$ MUR group had a greater force variability than the 50\%MUR before, but not after, the completion of the MUR. Recall that the 40\%MUR group had more motor units recruited than the 50\%MUR group before the completion of MUR. This result indicates that MUR is a more important factor in determining the relationship between force and force variability. It should be noted, however, that this finding does not mean that DR has no impact on force variability. When coefficient of variation (CV) for discharge rate and force variability were measured and examined, previous studies $[2,10]$ showed that $\mathrm{CV}$ for discharge rate plays a significant role in determining the $\mathrm{CV}$ for force. In addition, in a study of young and elderly force control [21], it was found that older adults had greater force fluctuations which are associated with greater relative power than young adults. They [21] attributed this difference in force control and relative power between the two groups to greater discharge rate variability of motor units in older adults. Previous studies $[2,14,22]$ have consistently showed that older adults exhibit greater discharge rate variability compared with young adults during a variety of motor tasks. In summary, DR also has significant effect on force fluctuations.

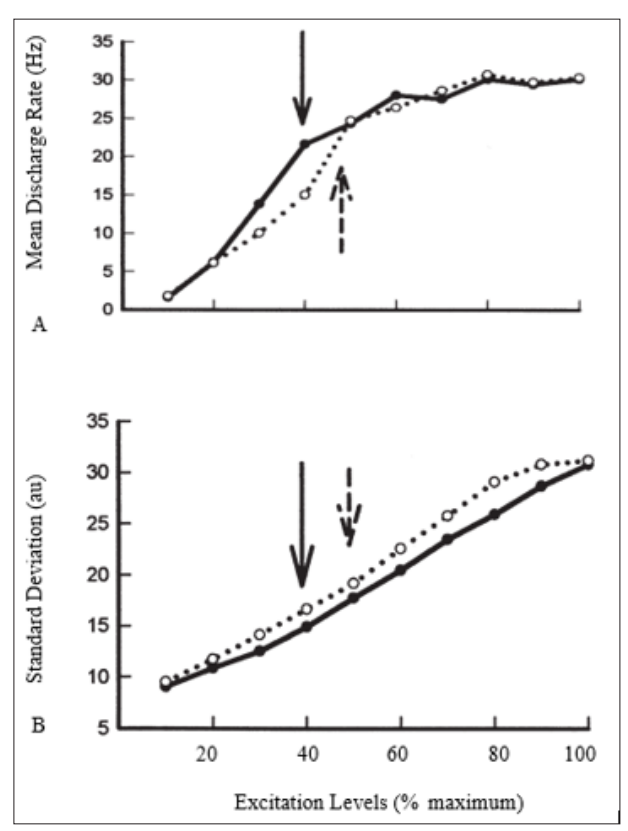

Figure 1: Simulated relationships between excitation level and mean discharge rate of all recruited motor units

(A), and excitation level and force variability for $40 \%$ MUR and 50\%MUR

(B). The arrows represent the excitation levels where motor-unit recruitment was completed for $40 \%$ MUR (solid arrows) and 50\% MUR (dashed arrows) [15].

\section{Synchronization}

Early studies have observed that weight lifters have a greater MUS index than skill- trained individual [23,24], and strength training resulted in increases of both muscle force and MUS [23]. These findings are interpreted as strong evidence to suggest that MUS is a contributing factor for the training-induced increase of muscle force. However, a recent computer simulation study [16] along with other experimental studies $[25,26]$ suggest that motor unit synchronization does not play a role in maximal muscle force. Instead, MUS is reported to have a significant effect on force fluctuations [15-17,26]. To this extent, a study [16] with simulated isometric contractions of a hand muscle found that force variability increased when MUS index increased. It is interesting to note that, in a separate but related simulation study [15], it was found that different levels of MUS between two simulated groups at high force levels (i.e., from $50 \%$ to $100 \%$ of MVC) did not result in differences in force variability between the two groups. Based on the findings from the two studies $[15,16]$, it is assumed that MUS has an effect on force variability, but its effect is not as significant as the effect of MUR.

\section{Conclusion}

Previous empirical studies [1-10] have consistently shown that force variability increases along with increasing levels of force. 
Furthermore, the increasing rate of force variability is faster at low force levels (i.e., less than 50\% MVC for small muscles) than at higher force levels (i.e, greater than 50\% MVC). Differences in the rate of increase of force variability is due to motor unit behavior such as MUR, DR, and MUS. Among the three behaviors of motor units, MUR produces the greatest impact on determining the relationship between force and force variability compared to DR and MUS.

\section{References}

1. Christou EA, Grossman M, Carlton LG (2002) Modeling variability of force during isometric contractions of the quadriceps femoris. Journal of Motor Behavior 34(1): 67-81.

2. Moritz Chet T, Barry Benjamin K, Pascoe Michael A, Enoka RM (2005) Discharge rate variability influences the variation in force fluctuations across the working range of a hand muscle. Journal of neurophysiology 93(5): 2449-2459.

3. Schmidt RA, Zelaznik HN, Hawkins B, Frank JS, Quinn JT Jr (1979) Motor output variability: A theory for the accuracy of rapid motor acts. Psychological Review 47(5): 415-441.

4. Sherwood DE, Schmidt RA (1980) The relationship between force and force variability in minimal and near-maximal static and dynamic contractions. Journal of Motor Behavior 12(1): 75-89.

5. Sherwood DE, Schmidt RA, Walter CB (1988) The force/force-variability relationship under controlled temporal conditions. Journal of Motor Behavior 20(2): 106-116.

6. Carlton LG, Newell KM (1988) Force variability in isometric tasks. In DA Winter, RW Norman, KC Hayes, RP Wells, A Patla (Eds.); Champaign, Human Kinetics, Biomechanics IX, pp. 128-132.

7. Newell KM, Carlton LG (1985) On the relationship between peak force and peak force variability in isometric tasks. Journal of Motor Behavior 17(2): 230-241.

8. Newell KM, Carlton LG (1988) Force variability in isometric responses. Journal of Experimental Psychology Human Perception and Performance 14(1): 37-44.

9. Slifkin AB, Newell KM (1999) Noise, information transmission, and force variability. Journal of Experimental Psychology Human Perception and Performance 25(3): 837-851.

10. Slifkin AB, Newell KM (2000) Variability and noise in continuous force production. Journal of Motor Behavior 32(2): 141-150.

11. Loscher WN, Gallasch E (1993) Myo-electric signals from two extrinsic muscles and force tremor during isometric hand grip. European Journal of Applied Physiology 67(2): 99-105.

\section{ISSN: 2574-1241}

DOI: $10.26717 / B J S T R .2018 .08 .001722$

Wan X Yao. Biomed J Sci \& Tech Res

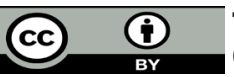

This work is licensed under Creative Commons Attribution 4.0 License

Submission Link: https://biomedres.us/submit-manuscript.php
12. Fitts PM (1951) Engineering psychology and equipment design. In SS Stevens (Eds.); Handbook of experimental psychology. New York, Wiley, pp. 1287-1340.

13. Fitts PM (1954) The information capacity of the human motor system in controlling the amplitude of movement. Journal of experimental Psychology 47: 381-391.

14. Laidlaw DH, Bilodeau M, Enoka RM (2000) Steadiness is reduced and motor unit discharge is more variable in old adults. Muscle Nerve 23(4): 600-612.

15. Yao Wan X (2004) Roles of motor-unit recruitment in producing force variability of simulated muscle contractions. Motor Control 8(1): 64-75.

16. Yao WX, Fuglevand AJ, Enoka RM (2000) Motor-unit synchronization increases EMG amplitude and decreases force steadiness of simulated contractions. Journal of Neurophysiology 83(1): 441-452.

17. Semmler JG, Steege JW, Kornatz KW, Enoka RM (2000) Motor-unit synchronication is not responsible for larger motor-unit forces in old adults. Journal of Neurophysiology 84(1): 358-366.

18. Seyffarth H (1940) The behavior of motor units in voluntary contraction. Skrifter utgitt av Det Norske Videnskaps Akademi i Olso I Mat Naturv Klasse.

19. De Luca CJ, Le Fever RS, McCue MP, Xenakis AP (1982) Behavior of human motor units in different muscles during linearly varying contractions. Journal of Physiology 329: 113-128.

20. Milner-Brown HS, Stein RB, Yemm R (1973) The orderly recruitment of human motor units during voluntary isometric contractions. Journal of Physiology 230(2): 359-370.

21. Fox EJ, Bawja HS, Kim C, Kennedy DM, Vaillancourt DE, et al. (2013) Modulation of Force below 1Hz: Age-Associated Differences and the Effect of Magnified Visual Feedback. PLOS ONE 8(2): e55970.

22. Tracy BL, Maluf KS, Stephenson JL, Hunter SK, Enoka RM (2005) Variability of motor unit discharge and force fluctuations across a range of muscle forces in older adults. Muscle Nerve 32(4): 533-540.

23. Milner-Brown HS, Stein RB, Lee RG (1975) Synchronization of human motor units: Possible roles of exercise and supraspinal reflexes. Electroencephalogr Cli Neurophysiol 38(3): 245-254.

24. Semmler JG, Nordstrom MA (1998) Motor unit discharge and force tremor in skill- and strength-trained individuals. Exp Brain Res 119(1): 27-38.

25. Semmler JG, Sale MV, Kidgell DJ (2006) Motor unit synchronization measured by cross-correlation is not increased with strength training of a hand muscle. Proc Int Australas Winter Conf Brain Res 24: 2-5.

26. Kidgell D, Sale MV, Semmler JG (2017) Motor unit synchronization measured by cross-correlation is not influenced by short-term strength training of a hand muscle. Exp Brain Res 175(4): 745-53.

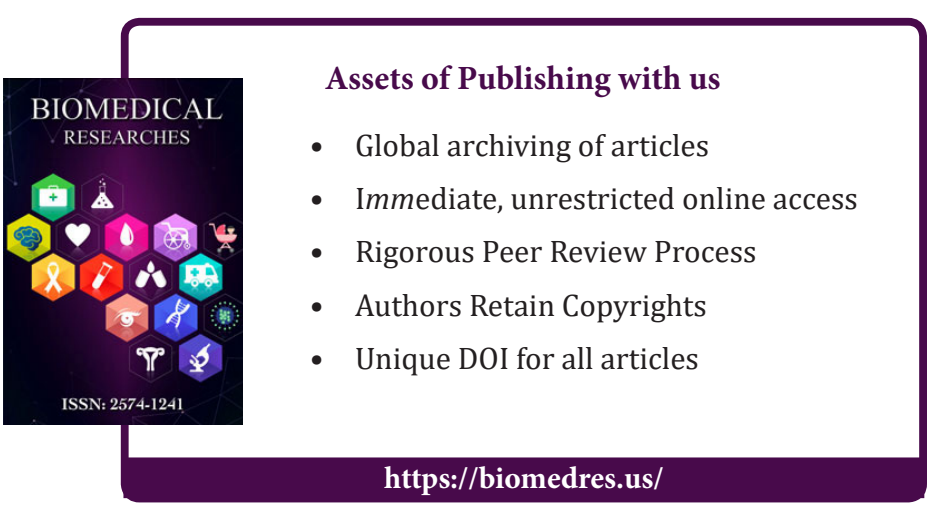

